\title{
Adjuvant chemotherapy after surgery for pancreatic ductal adenocarcinoma: retrospective real-life data
}

\author{
Sophia Chikhladze ${ }^{1 *}$, Ann-Kathrin Lederer ${ }^{1,2}$ (D) Lampros Kousoulas ${ }^{1}$, Marilena Reinmuth', Olivia Sick', \\ Stefan Fichtner-Feigl ${ }^{1}$ and Uwe A. Wittel ${ }^{1}$
}

\begin{abstract}
Background: The recommendation for postoperative chemotherapy in pancreatic ductal adenocarcinoma (PDAC) is based on prospective randomized trials. However, patients included in clinical trials do not often reflect the overall patient population treated in clinical practice.

Materials and methods: A retrospective review of all patients undergoing pancreas resection for PDAC between 2001 and 2013 was performed. Follow-up data from oncologists, general practitioners, or hospital patient files were available for $92 \%$ of patients.

Results: A total of 251 patients were included in our analysis. Chemotherapy was recommended for 223 patients, but 86 patients did not follow the recommendation. The application of the recommended chemotherapy, consisting of 6 cycles of gemcitabine, was only applied to 45 patients. Forty patients received the recommended number of cycles with dose reduction or prolonged intervals between cycles, and adjuvant chemotherapy was terminated prior to the intended completion of all 6 cycles in 54 patients. Survival of patients after adjuvant chemotherapy was increased compared to that of patients without chemotherapy (with recurrence 25.6 vs. 14.3 months, $p=0.001$, and without recurrence 27.4 vs. 14.3 months, $p<0.001)$. Terminating chemotherapy prior to completion $(p=0.009)$ as well as a lower number of chemotherapy cycles $(p=0.026)$ was associated with a decreased survival.

Conclusion: Adjuvant chemotherapy improves overall and disease-free survival after curative pancreatic resection, but only a small fraction of patients completes the recommended 6 cycles of adjuvant chemotherapy. Our data indicates that performance status of patients after pancreas resections for PDAC requires not only highly biologically active but also well-tolerated adjuvant chemotherapy regimens.
\end{abstract}

Keywords: PDAC, Chemotherapy, Outcome, Mortality, Survival, Pancreas surgery

\section{Introduction}

Pancreatic ductal adenocarcinoma (PDAC) is one of the most aggressive malignant neoplasms with a poor survival rate [1]. The only potential curative treatment is the surgical resection, which can be performed in less than $20 \%$ of the patients as the majority of patients are diagnosed at late stages with locally advanced tumors or even with distant metastases [2]. Despite all treatment

\footnotetext{
* Correspondence: sophia.chikhladze@uniklinik-freiburg.de

${ }^{1}$ Department of General and Visceral Surgery, Medical Center - University of Freiburg, Faculty of Medicine, University of Freiburg, Hugstetter Straße 55, 79106 Freiburg im Breisgau, Germany

Full list of author information is available at the end of the article
}

advances in the field of pancreatic cancer, the 5-year survival is estimated to be as low as 5\% [3]. Adjuvant chemotherapy is the standard of care following surgical resection of PDAC, with numerous studies showing improved long-term survival of patients treated with adjuvant chemotherapy $[4,5]$. Recommended by guidelines is that, in order to be able to receive adjuvant chemotherapy, patients must have recovered from pancreatic surgery and need to be in a good physical condition $[6,7]$. The recovery from surgery is delayed because of postoperative complications that despite reduced mortality remain common. Serious complications are initiated by pancreatic surgery in up to $20 \%$ of the patients $[7,8]$. As a

(c) The Author(s). 2019 Open Access This article is distributed under the terms of the Creative Commons Attribution 4.0 International License (http://creativecommons.org/licenses/by/4.0/), which permits unrestricted use, distribution, and 
consequence, $30 \%$ of patients who are primarily eligible for adjuvant chemotherapy are never treated, mostly due to the presence of major comorbidities or due to postoperative complications after pancreas resection $[7,9,10]$. But also in patients with complication-free postoperative course, about $40 \%$ do not receive the complete treatment or require dose-reduction due to chemotherapy-related toxicity and adverse events $[4,11]$. The aim of this singlecenter study was to evaluate the effect of adjuvant chemotherapy on long-term survival of patients after pancreatic resection for ductal adenocarcinoma. We also focused on the number of chemotherapy applications performed, reasons leading to an early termination of the adjuvant chemotherapy, and impact of the early termination of adjuvant chemotherapy on the survival of the patients.

\section{Methods}

This study is a monocentric, retrospective cohort study at the Department of General and Visceral Surgery of the University Hospital. From November 2001 to December 2012, all patients, undergoing pancreas resection due to pancreatic ductal adenocarcinoma (PDAC) with curative intend, were retrospectively screened. The study was performed according to the principles of the Declaration of Helsinki and was approved by the ethical committee of the Medical Faculty of the University.

\section{Criteria of inclusion and exclusion}

For inclusion, curative intend had to be stated and PDAC had to be histopathologically proven. All subtypes and localizations of ductal adenocarcinoma as well as all kind of surgical procedures were considered. Patients, who received neoadjuvant chemotherapy or radiation, were not enrolled as well as patients, who died during the hospital stay.

\section{Data acquisition and outcome measures}

Data was obtained from in-house medical records and from the database of the comprehensive cancer center, as well as follow-up reports from oncologists and general practitioners. Examined parameters included patients' demographics; overall, 5-year, and disease-free survival; postoperative complications; and tumor and treatment characteristics such as type and course of operation. Furthermore, the application of adjuvant chemotherapy or reasons for not applying and premature termination of adjuvant chemotherapy were captured. Primary aim was the impact of number of adjuvant chemotherapy cycles on long-term survival of patients after pancreatic resection to clarify the hypothesis whether more cycles might improve survival.

\section{Statistical analysis}

Parameters were documented and analyzed using IBM SPSS for Windows (Version 22.0), and statistical significance was tested using Mann-Whitney $U$ test for continuous and the chi-square tests as well as the Fisher's exact test for categorical variables. Overall survival was analyzed using the KaplanMeier method with post hoc log-rank tests. Multivariate survival analysis was performed with the Cox proportional hazard model. $p<0.05$ was considered significant. Results are presented as median values unless otherwise specified.

\section{Results}

Overall, a total of 251 PDAC patients after pancreatic resection with curative intent were included in the analysis (see Table 1). Follow-up was available for 92\% $(n=232)$ of the patients, whereas $80 \%(n=186)$ completed 5-year follow-up. Median age was 67 years (range 30-88 years), and slightly more patients were female $(n=131,52 \%)$ than male $(n=120,47 \%)$. More than three quarters of the patients $(n=194,77 \%)$ suffered from cardiovascular, pulmonary, renal, or hepatic diseases leading to an ASA classification of II in $60 \%$ and of III in $32 \%$ of the cohort [12]. The median duration between diagnosis and operation lasted 23 days (range 3-241 days). TNM classification of patients is shown in Table 2 [13]. Most tumors were located in the head $(n=209,83 \%)$, followed by the $(n=26,10 \%)$ and body $(n=16,6 \%)$. Correspondingly, 190 (76\%) patients received pancreatic head resections, 29 (13\%) distal pancreas resections and 29 (12\%) total pancreatectomies. Tumor diameter was on average $2.7 \mathrm{~cm}$. The median operation duration was $421 \mathrm{~min}$ (range 140-717 min). Eighteen (7\%) suffered from intraoperative complications and 143 (57\%) suffered from diverse postoperative complications, leading to an operative revision in 38 (15\%) patients. Patients stayed in the intensive care unit for 5 days (range 132 days). The median overall hospital stay was 18 days (range 7-63 days). Drains were removed after 7 days (range $0-62$ days).

\section{Chemotherapy treatment}

In 223 (89\%) patients, adjuvant chemotherapy was recommended (suggested by interdisciplinary tumor board), but only $62 \%(n=137)$ of the patients finally received adjuvant chemotherapy. Two patients (7\%) without recommendation for adjuvant chemotherapy received it leaving 139 (56\%) patients with adjuvant chemotherapy after pancreas resection. Application of adjuvant chemotherapy had an impact on overall survival (see Fig. 1, $p=$ $0.001)$. In $33 \%(n=27)$ of patients with recommended but not delivered adjuvant chemotherapy, tumor recurrence or metastases were detected prior to the initiation 
Table 1 Patients' demographics of all included patients after curative intended pancreas surgery due to pancreatic ductal adenocarcinoma $(n=251)$

\begin{tabular}{|c|c|}
\hline & Median (range) \\
\hline Age (years) & $67(30-88)$ \\
\hline \multirow[t]{2}{*}{$\mathrm{BMI}\left(\mathrm{kg} / \mathrm{m}^{2}\right)$} & $24.6(15-39)$ \\
\hline & $n(\%)$ \\
\hline Gender (female/male) & $131 / 120(52 \% / 48 \%)$ \\
\hline Smokers & $53(21 \%)$ \\
\hline Alcohol abuse & $28(11 \%)$ \\
\hline \multicolumn{2}{|l|}{ ASA Score [12] } \\
\hline । & $13(5 \%)$ \\
\hline$\|$ & $152(61 \%)$ \\
\hline III & $81(33 \%)$ \\
\hline IV & $3(1 \%)$ \\
\hline \multicolumn{2}{|l|}{ Common comorbidities } \\
\hline Hypertension & $133(54 \%)$ \\
\hline Post pancreatitis & $125(50 \%)$ \\
\hline Hepatic disease & $100(40 \%)$ \\
\hline Coronary heart disease & $43(17 \%)$ \\
\hline Pulmonary disease & $33(13 \%)$ \\
\hline Renal insufficiency & $30(12 \%)$ \\
\hline Diabetes & $28(11 \%)$ \\
\hline \multicolumn{2}{|l|}{ Localization of tumor } \\
\hline Head & $209(83 \%)$ \\
\hline Body & $16(7 \%)$ \\
\hline Tail & $26(10 \%)$ \\
\hline \multicolumn{2}{|l|}{ Type of surgery } \\
\hline Pancreatoduodenectomy & $190(76 \%)$ \\
\hline Distal pancreatectomy & $29(13 \%)$ \\
\hline Total pancreatectomy & $32(11 \%)$ \\
\hline \multicolumn{2}{|l|}{ Complications } \\
\hline Intraoperative complication & $18(7 \%)$ \\
\hline Postoperative complication & $143(57 \%)$ \\
\hline \multirow[t]{2}{*}{ Operative revision } & $38(15 \%)$ \\
\hline & median (range) \\
\hline \multicolumn{2}{|l|}{ Hospital stay (days) } \\
\hline Overall & $18(7-63)$ \\
\hline Intensive care unit & $5(1-32)$ \\
\hline Drain remove (days) & $7(0-62)$ \\
\hline
\end{tabular}

of adjuvant chemotherapy. Further reasons for not delivering adjuvant chemotherapy were poor general condition $(n=17,21 \%)$ or personal reasons $(n=13,16 \%)$. Postoperative complications were only in $9 \%(n=7)$ of the patients the cause for not applying adjuvant chemotherapy. On average, chemotherapy was
Table 2 Final TNM classification of pancreatic ductal adenocarcinomas of all included patients after curative intended pancreas surgery $(n=251)$

\begin{tabular}{|c|c|c|c|c|c|c|c|c|c|}
\hline & & G & $\mathrm{T}$ & $N$ & M & $\mathrm{Pn}$ & $L$ & V & $\mathrm{R}$ \\
\hline \multirow[t]{2}{*}{0} & $n$ & & & 68 & 242 & 44 & 60 & 163 & 181 \\
\hline & $\%$ & & & 27 & 96 & 18 & 24 & 65 & 72 \\
\hline \multirow[t]{2}{*}{1} & $n$ & 7 & 6 & 183 & 8 & 157 & 132 & 39 & 67 \\
\hline & $\%$ & 3 & 3 & 73 & 3 & 63 & 53 & 16 & 27 \\
\hline \multirow[t]{2}{*}{2} & $n$ & 158 & 16 & & & & & 2 & 3 \\
\hline & $\%$ & 63 & 6 & & & & & 1 & 1 \\
\hline \multirow[t]{2}{*}{3} & $n$ & 83 & 218 & & & & & & \\
\hline & $\%$ & 33 & 87 & & & & & & \\
\hline \multirow[t]{3}{*}{4} & $n$ & 3 & 9 & & & & & & \\
\hline & $\%$ & 1 & 4 & & & & & & \\
\hline & Overall & 251 & 251 & 251 & 250 & 201 & 192 & 204 & 251 \\
\hline
\end{tabular}

$G$ grade of tumor cells, $T$ tumor size, $N$ lymph node manifestation, $M$ distant metastases, $P n$ perineural invasion, $I$ invasion into lymphatic vessels, $V$ invasion into veins, $R$ status of resection

delivered later than recommended. The median for starting adjuvant chemotherapy was 8.5 weeks after the operation while studies recommended 6-8 weeks postoperatively. In contrast to not applying chemotherapy, postoperative complications were frequently the reason for delaying chemotherapy $(p=0.011)$. To that respect, delayed removal of abdominal drains (> 7 days, $p=0.011$ ) and prolonged hospital stay ( $>18$ days, $p<0.001)$ were found responsible. In line with the recommendation in the treatment period, gemcitabine (GEM) was applied as monotherapy in 95\% $(n=130)$ of patients. Three $(2 \%)$ patients had a therapy with the combination of GEM and 5-fluorouracil (5-FU) and two (2\%) patients had a monotherapy with 5-FU. Additional two (2\%) patients had a therapy with the combination of GEM and erlotinib. More than $60 \%(n=84)$ of treated patients received 6 cycles of chemotherapy (Fig. 2). Overall, 54 (39\%) out of 139 patients, who received adjuvant chemotherapy, terminated the therapy prior to finishing 6 cycles. Reasons for premature termination of adjuvant chemotherapy were toxicity of the applied medication $(n=13,24 \%)$ or recurrence $(n=18,33 \%)$. Forty-one percent $(n=22)$ premature termination of chemotherapy was undertaken due to patient wish. When adjuvant chemotherapy was terminated early, recurrence-free survival was decreased from 12.2 to 6.9 months $(p=0.005)$ even when patients with recurrence less than 1 month postoperatively were excluded. In 40 (29\%) patients, the anticipated dose of GEM had to be reduced, cycles elongated or, medication had to be changed. Patients with 6 cycles of chemotherapy showed a median overall survival of 


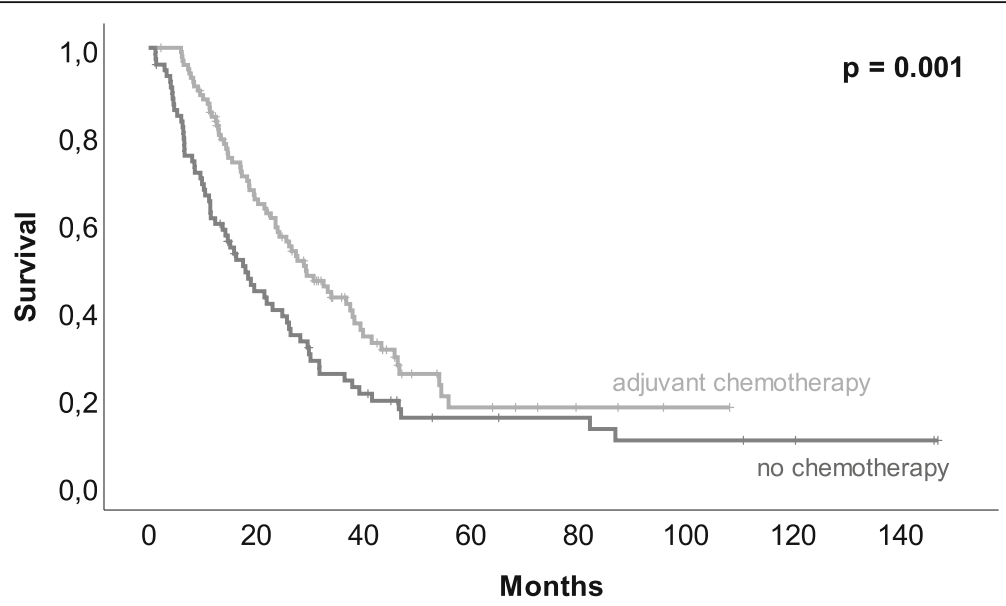

Fig. 1 Kaplan-Meier estimator of patients with and without adjuvant chemotherapy. Adjuvant chemotherapy after pancreas surgery due to pancreatic ductal adenocarcinoma led to a significantly better survival (14.3 vs. 25.6 months, $p=0.001$ )

27.7 months. Twenty-one (15\%) patients that received 4-5 cycles showed a median survival of 26 months, and $33(24 \%)$ of patients receiving only $1-3$ cycles had a median survival of 14 months (Fig. 3). Median overall survival was not affected by delayed initiation of chemotherapy ( $>8$ weeks, $n=71, p=0.510$ ) or dose reduction, conversion of medication, or prolonged interval between chemotherapy applications $(n=40$, $p=0.449)$.

Forty percent $(n=56)$ of patients received adjuvant chemotherapy in our hospital, and 60\% $(n=83)$ were treated by an oncologist in private practice. External oncologists performed dose reductions approx. 2.5 times more frequent than oncologists associated to the university hospital. Patients with dose reduction $(n=40)$ were more frequently treated external $(n=29,73 \%)$ than in our hospital $(n=11,27 \%, p=0.097)$.

\section{Subgroup analysis of long-term survivors ( $>5$ years)}

Until the end of follow-up, only eight patients (3\%) were alive and in complete remission (CR). In all cases, CR lasted for more than 5 years and they did not develop any recurrence. Only four of these patients had full recommended chemotherapy regimen (6 cycles of GEM, full dosage). Patients' characteristics are shown in Table 3. Due to small sample size, we waived further statistical analysis of these patients.

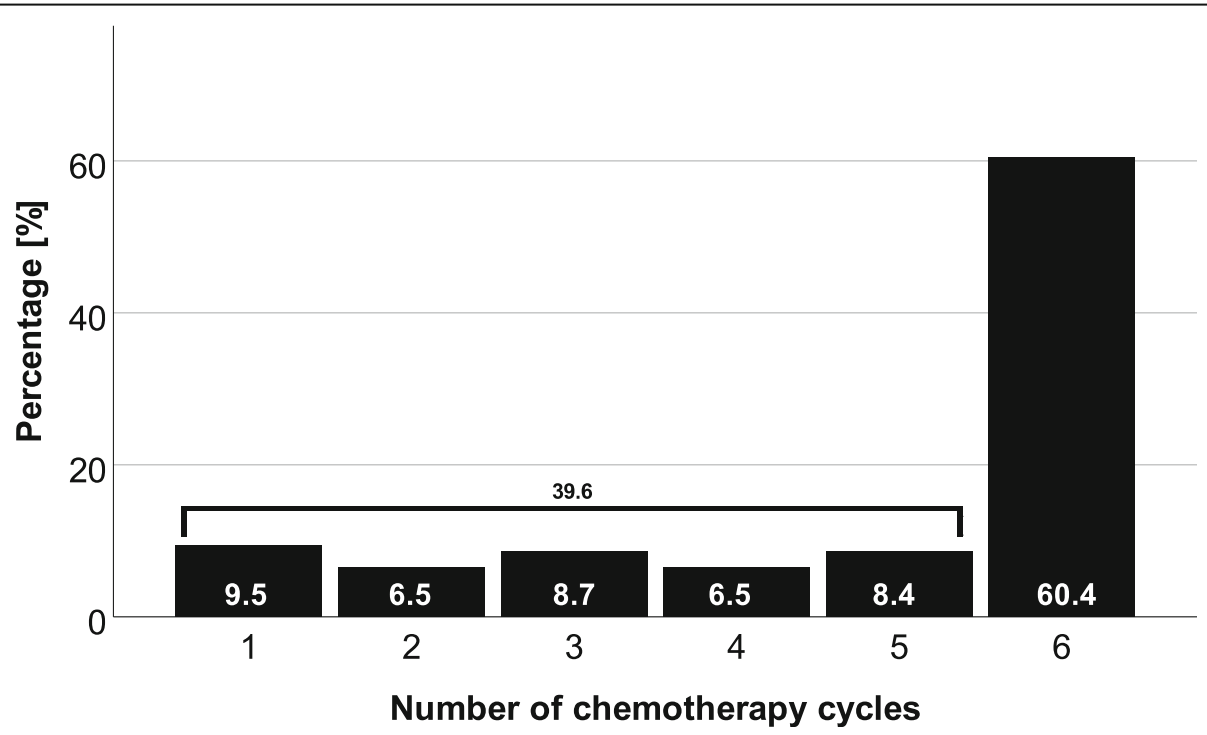

Fig. 2 Distribution of patients related to the number of chemotherapy cycles. More than half of patients (60\%) received 6 cycles of chemotherapy as it is recommended 


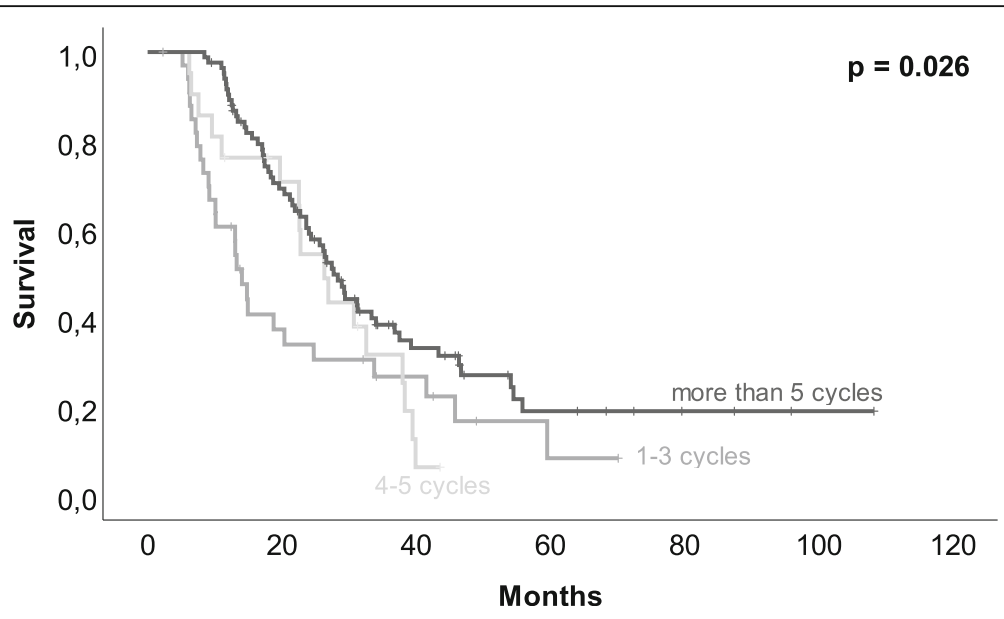

Fig. 3 Kaplan-Meier estimator of the relation between the number of chemotherapy cycles and survival. Patients with 6 cycles of chemotherapy showed a median overall survival of more than 27 months, with 4-5 cycles of 26 months and with 1-3 cycles of 14 months $(p=0.026)$

\section{Concordance of tumor marker and survival}

The pancreas-specific tumor marker CA 19.9 was increased in $165(66 \%)$ patients preoperatively. The median concentration of CA 19.9 was 113 (95\% CI $509-1304) \mathrm{U} / \mathrm{mL}$ at the time of diagnosis. Preoperative CA 19.9 of more than $500 \mathrm{U} / \mathrm{mL}(n=61,27 \%)$ was associated with decreased overall survival (12.8 vs. 22.6 months, $p=0.012$ ) as well as with decreased 3 -year survival rate $(8$ vs. $27 \%, p=0.001)$. The recurrence-free survival of patients with a preoperatively CA 19.9 of more than $500 \mathrm{U} / \mathrm{mL}$ was 5.5 (range 5-9) months compared to 10.1 (range 10-14) months of patients with lower values $(p=0.475)$. CA 19.9 decreased to $25(95 \%$ CI $220-1021) \quad \mathrm{U} / \mathrm{mL}$ after pancreas resection. Patients $(n=80,38 \%)$ without normalization of CA 19.9 (<37 U/I) postoperatively had a significantly lower overall survival than patients $(n=131,62 \%)$ with normalization $(p=0.001)$. Overall survival of patients with normalized CA 19.9 postoperatively was 26.4 (range 7-87) months compared to 17.2 (range 1-82) months of patients without normalization $(p<0.001)$. The recurrence-free survival of postoperatively normalized patients was 12.2 (range 0-82) months compared to 5.3 (range 0-28) months of non-normalized patients $(p<0.001)$. The higher CA 19.9, the shorter was survival (preoperative: $r=-0.177, p=0.007$, postoperative: $r=-0.147$, $p=0.32$ ). Upon recurrence, CA 19.9 increased to 147 (95\% CI $724-3523) \mathrm{U} / \mathrm{mL}$. CA 19.9 of more than 500 $\mathrm{U} / \mathrm{mL}(n=55,33 \%)$ at the time of recurrence diagnosis showed a slightly but non-significant decreased overall survival $(13.0$ vs. 23.6 months, $p=0.081)$ as well as a significant decreased 3-year survival rate (7 vs. $23 \%, p=0.01$ ).

\section{Recurrence and survival}

Diagnosis of recurrence was made in 193 (83\%) of 232 follow-up data patients with a median disease-free survival of 7.8 months (range $0-83$ months) after resection of the pancreatic tumor. Median disease-free survival was significantly affected by adjuvant chemotherapy and found to be 4.1 months after operation in patients without adjuvant chemotherapy $(n=84)$ and 10.9 months in patients with chemotherapy $(n=139, p=0.01)$. The majority of patients $(n=85,44 \%)$ suffered from distant metastases, followed by the combination of distant metastases and local recurrence $(n=84,43 \%)$. Sole local recurrence was only found in 13\% $(n=25)$ of patients. Distant metastases were found in the liver $(n=95,49 \%)$, lymph nodes $(n=75,39 \%)$, peritoneum $(n=71,37 \%)$, and lung $(n=50,26 \%)$. Subgroup analysis of influence of site-specific metastases on survival showed that lung metastases were associated with a better survival compared to metastases of the liver $(p=0.043$, see Fig. 4). Patients with lung metastases $(n=11)$ had an overall survival of 31.0 (range 7-46) months compared to 22.0 (range 4-47) months of patients with liver metastases $(n=21)$.

The median overall survival was 18.5 (range 1-147) months. One-year survival rate was $69 \%$, decreasing to $21 \%$ after 3 years and to $6 \%$ after 5 years. Almost $90 \%$ $(n=171,87 \%)$ of the patients died of tumor progression or tumor-related complications. The cause of death of $23(12 \%)$ patients is unknown. Only three patients (1\%) died not to tumor-related causes (myocardial infarction, vasovagal asystole, and stroke). The most common tumor-related cause of death was a worsening of general condition presenting as increasing weakness, fatigue, and immobility in 135 patients (69\%). Twenty-eight percent 
Table 3 Subgroup analysis of long-term survivors in complete remission with $(C T x, n=4)$ and without completion of full recommended chemotherapy regimen (no CTx, $n=4$ )

\begin{tabular}{|c|c|c|}
\hline & $C T x$ & noCTx \\
\hline & Median (range) & Median (range) \\
\hline Age (years) & $69(65-70)$ & $57(30-84)$ \\
\hline \multirow[t]{2}{*}{$\mathrm{BMI}\left(\mathrm{kg} / \mathrm{m}^{2}\right)$} & $23.4(23-32)$ & $24.5(23-25)$ \\
\hline & $n(\%)$ & \\
\hline Gender (female/male) & $4 / 0(100 / 0 \%)$ & $3 / 1(75 / 25 \%)$ \\
\hline Smokers & $0(0 \%)$ & $1(25 \%)$ \\
\hline Alcohol abuse & $0(0 \%)$ & $0(0 \%)$ \\
\hline \multicolumn{3}{|l|}{ ASA Score [12] } \\
\hline 1 & $1(25 \%)$ & $0(0 \%)$ \\
\hline$\|$ & $2(50 \%)$ & $2(50 \%)$ \\
\hline III & $1(25 \%)$ & $2(50 \%)$ \\
\hline IV & $0(0 \%)$ & $0(0 \%)$ \\
\hline \multicolumn{3}{|l|}{ Common comorbidities } \\
\hline Hypertension & $1(25 \%)$ & $3(75 \%)$ \\
\hline Post pancreatitis & $2(50 \%)$ & $2(50 \%)$ \\
\hline Hepatic disease & $1(25 \%)$ & $0(0 \%)$ \\
\hline Coronary heart disease & $0(0 \%)$ & $0(0 \%)$ \\
\hline Pulmonary disease & $0(0 \%)$ & $0(0 \%)$ \\
\hline Renal insufficiency & $0(0 \%)$ & $1(25 \%)$ \\
\hline Diabetes & $1(25 \%)$ & $0(0 \%)$ \\
\hline \multicolumn{3}{|l|}{ Localization of tumor } \\
\hline Head & $3(75 \%)$ & $4(100 \%)$ \\
\hline Body & $1(25 \%)$ & $0(0 \%)$ \\
\hline Tail & $0(0 \%)$ & $0(0 \%)$ \\
\hline \multicolumn{3}{|l|}{ Grading of tumor } \\
\hline $\mathrm{G} 2$ & $3(75 \%)$ & $4(100 \%)$ \\
\hline G3 & $0(0 \%)$ & $0(0 \%)$ \\
\hline G4 & $1(25 \%)$ & $0(0 \%)$ \\
\hline \multicolumn{3}{|l|}{ Invasion of lymph nodes (N) } \\
\hline NO & $2(50 \%)$ & $2(50 \%)$ \\
\hline N1 & $2(50 \%)$ & $2(50 \%)$ \\
\hline \multicolumn{3}{|l|}{ Type of surgery } \\
\hline Pancreatoduodenectomy & $3(75 \%)$ & $4(100 \%)$ \\
\hline Distal pancreatectomy & $1(25 \%)$ & $0(0 \%)$ \\
\hline Total pancreatectomy & $0(0 \%)$ & $0(0 \%)$ \\
\hline \multicolumn{3}{|l|}{ Complications } \\
\hline Intraoperative complication & $0(0 \%)$ & $0(0 \%)$ \\
\hline Postoperative complication & $3(75 \%)$ & $2(50 \%)$ \\
\hline \multirow[t]{2}{*}{ Operative revision } & $0(0 \%)$ & $0(0 \%)$ \\
\hline & Median (range) & Median (range) \\
\hline \multicolumn{3}{|l|}{ Hospital stay (days) } \\
\hline Overall & $17(14-45)$ & $21(16-31)$ \\
\hline Intensive care unit & $5(3-6)$ & $7(4-7)$ \\
\hline Drain remove (days) & $6(3-45)$ & $7(5-8)$ \\
\hline
\end{tabular}

$(n=55)$ suffered from tumor cachexia and 12\% $(n=24)$ from infections. Nearly half of the deceased $(n=92$, $46 \%)$ had an organ failure such as a respiratory insufficiency $(n=36,18 \%)$, renal insufficiency $(n=17,9 \%)$, or a liver failure $(n=38,19 \%)$. Ascites occurred in 30\% $(n=$ 58) of the deceased.

\section{Multivariate risk analysis (see Table 4)}

The multivariate analysis showed that the absence of lymph node invasion $(p=0.012)$, of lymph vessel or vein invasion $(p=0.014$ and $p=0.016)$, and distant metastases $(p<0.001)$ were associated with longer overall survival. A higher tumor grading (G1/G2, $p=0.019)$ as well as $\mathrm{R} 0$ resection $(p<0.001)$ improved survival.

\section{Discussion}

Prognosis of PDAC is, due to late diagnosis, rapid tumor progression, and frequent recurrence, limited. Pancreatic surgery followed by adjuvant chemotherapy improves survival and is the only chance for curative treatment. Despite a defined and guidelinerecommended therapeutic strategy, the prognosis remains poor. It is known that postoperative complications and a delayed recovery after pancreatic surgery lead to adjuvant chemotherapy omission and treatment delays [7]. Initiation of adjuvant chemotherapy is recommended 6-8 weeks postoperatively, which was, due to various factors, frequently not able in our patients. Delayed initiation of chemotherapy has been reported previously. Merkow et al. observed an initiation of adjuvant chemotherapy with a median time to adjuvant therapy of 52 days ( 7.4 weeks) in patients without postoperative complications. In patients with complications, the delay was even 70 days [7]. The retrospective analysis of clinical data reveals that the recommended duration between surgery and initiation of chemotherapy is likely to be met only in a subset of patients. Nevertheless, survival analysis of our data showed no association between delayed treatment and decreasing survival, which is confirmed by other studies [14]. Timing of chemotherapy is not as crucial as an adequate number of cycles $[14,15]$. Our results showed that more than 3 cycles after curative pancreas surgery were associated with better survival. Interestingly, the benefit of more than 5 cycles was smaller and patients with 4-5 and with 6 cycles had a comparable survival. Contrary to that, Epelboym et al. found that survival is increased after 6 cycles or more cycles of adjuvant chemotherapy [15]. However, they only differentiated between 1 and 5 and 6 and more cycles, which is different to our analysis. For other cancers, it has been reported 


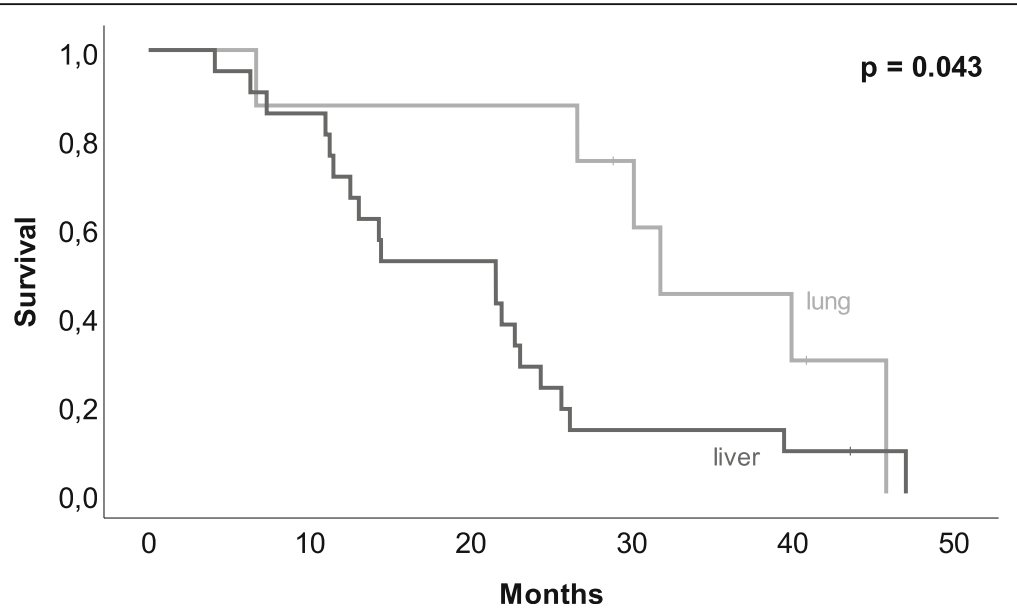

Fig. 4 Kaplan-Meier-estimator of site-specific overall surgical, comparison of lung metastasis and liver metastasis. Patients with lung metastases showed a significantly better survival than patients with liver metastasis $(p=0.046)$

that more cycles do not necessarily lead to an increased survival [16, 17]. Nevertheless, it must be considered that the results might be influenced by patients' comorbidities. Only patients in good condition are able to be treated with chemotherapy. It is even more surprising that patients treated with $4-5$ cycles had nearly the same survival time than patients with 6 cycles as it is assumable that the patients with fewer cycles quitted therapy due to poor condition or intolerable side effects.

Subgroup analysis of lung metastatic patients compared to liver metastatic patients showed sitespecific influence on survival. Despite small sample size, we found an improved overall survival of patients with lung metastases compared to patients with liver metastases, confirming the results of a previously published database analysis of metastatic pancreatic cancer patients with real-life data of initially curative treated patients [18]. Further analysis of our patients showed just tendencies of demographic and clinical differences prior to diagnosis of pancreatic cancer, but due to the small sample size, we are not able to draw firm conclusions. However, future research should include molecular genetic data [19], which is not available in the patients of our study, who were treated between 2001 and 2012, where molecular genetic analysis was not performed as standard.

Due to the retrospective nature, GEM had been applied to $95 \%$ of the patients which was in line with past guidelines for chemotherapy treatment of PDAC $[4,20]$. Based on novel findings and significantly improved survival, this recommendation will change to a modified treatment with FOLFIRINOX [21, 22]. Our retrospective analysis, however, indicated that already a substantial number of patients are not able to receive full guideline-recommended chemotherapy. For these patients, the beneficial toxicity profile of GEM will remain a valid option for adjuvant chemotherapy. Additionally, our data questions the general applicability of adjuvant mFOLFIRINOX in the overall cohort of resected pancreatic cancer patients since $62 \%$ of our patients received adjuvant chemotherapy at all and only $20 \%$ received all cycles without dose reduction. Our data is supported by another publication reporting adjuvant chemotherapy in slightly more than half of the patients after curative intended pancreatic surgery [7].

\section{Limitations}

Our retrospective analysis is limited by its monocentric study design and a small sample size as well as by lack of documentation and documentation errors, but only $8 \%$ of patients were lost to follow-up. The large time span for collecting the data and change of guidelines affected the treatment recommendations given and the intensity by which the indication for adjuvant therapy was explained to the patient. For identifying reasons for terminating chemotherapy, heterogeneous documentation received from different sources had to be used.

\section{Conclusion}

Adjuvant chemotherapy improves long-term and disease-free survival after curative pancreatic resection, but only a small fraction of patients completes the recommended 6 months of adjuvant 
Table 4 Multivariate risk analysis. Impact of various characteristics on overall survival of all included patients with pancreatic ductal adenocarcinoma after curative intended pancreas surgery $(n=251)$

\begin{tabular}{|c|c|c|c|c|}
\hline & & Survival [months] & $\mathrm{Cl}$ [months] & $p$ \\
\hline \multirow[t]{2}{*}{ Gender } & Male & 19.6 & $16.2-23.1$ & 0.705 \\
\hline & Female & 21.9 & $16.8-27.0$ & \\
\hline \multirow[t]{3}{*}{ Age [years] } & $<63$ & 22.8 & 14.9-30.7 & 0.085 \\
\hline & $<72$ & 22.5 & $17.7-27.4$ & \\
\hline & $\geq 72$ & 17.6 & $13.7-21.4$ & \\
\hline \multirow[t]{2}{*}{$\mathrm{BMI}\left[\mathrm{kg} / \mathrm{m}^{2}\right]$} & $>24,6$ & 18.7 & $16.1-21.3$ & 0.903 \\
\hline & $\geq 24,6$ & 21.9 & $18.2-25.6$ & \\
\hline \multirow[t]{2}{*}{ Weight loss [kg] (preoperatively) } & $<5$ & 19.0 & $14.5-23.5$ & 0.878 \\
\hline & $\geq 5$ & 21.2 & $17.1-25.3$ & \\
\hline \multirow[t]{2}{*}{ Comorbidities } & Yes & 20.7 & $17.5-24.0$ & 0.464 \\
\hline & No & 19.5 & 7.9-31.2 & \\
\hline \multirow[t]{2}{*}{ Pancreatitis (preoperatively) } & Yes & 18.5 & $14.3-22.7$ & 0.395 \\
\hline & No & 22.5 & $18.1-27.0$ & \\
\hline \multirow[t]{2}{*}{ Diabetes (postoperatively) } & Yes & 21.2 & $15.8-26.5$ & 0.565 \\
\hline & No & 20.3 & $16.2-24.5$ & \\
\hline \multirow[t]{4}{*}{ ASA [12] } & I & 20.4 & $11.1-29.6$ & 0.732 \\
\hline & $\|$ & 21.5 & $17.8-25.2$ & \\
\hline & III & 19.7 & $13.5-25.3$ & \\
\hline & IV & 12.1 & $3.1-21.1$ & \\
\hline \multirow[t]{2}{*}{ Alcohol } & Yes & 19.7 & $2.7-23.5$ & 0.585 \\
\hline & No & 17.2 & $17.2-23.5$ & \\
\hline \multirow[t]{2}{*}{ Nicotine } & Yes & 22.8 & $16.3-29.2$ & 0.661 \\
\hline & No & 19.7 & $16.2-23.2$ & \\
\hline \multirow[t]{2}{*}{ Diagnosis to OP [days] } & $<23$ & 20.4 & $16.5-24.2$ & 0.817 \\
\hline & $\geq 23$ & 20.4 & $15.6-25.1$ & \\
\hline \multirow[t]{2}{*}{ Duration of OP [min] } & $<400$ & 19.6 & $16.5-22.7$ & 0.505 \\
\hline & $\geq 400$ & 21.9 & $16.8-27.1$ & \\
\hline \multirow[t]{2}{*}{ ICU stay [days] } & $<5$ & 19.4 & $13.7-25.1$ & 0.837 \\
\hline & $\geq 5$ & 20.4 & $14.6-26.1$ & \\
\hline \multirow[t]{2}{*}{ Hospital stay [days] } & $<18$ & 20.8 & $16.2-25.4$ & 0.147 \\
\hline & $\geq 18$ & 20.4 & $16.4-24.3$ & \\
\hline \multirow[t]{2}{*}{ Drain removal [days] } & $<7$ & 19.6 & $15.6-23.5$ & 0.075 \\
\hline & $\geq 7$ & 20.4 & $16.1-24.6$ & \\
\hline \multirow[t]{2}{*}{ Complications (intraoperatively) } & Yes & 17.4 & $14.2-20.6$ & 0.385 \\
\hline & No & 21.2 & $18.2-24.2$ & \\
\hline \multirow[t]{2}{*}{ Complications (postoperatively) } & Yes & 21.9 & $15.1-28.7$ & 0.994 \\
\hline & No & 20.4 & $18.2-22.5$ & \\
\hline \multirow[t]{2}{*}{ Blood transfusion (intraoperatively) } & Yes & 13.4 & $3.0-23.8$ & 0.118 \\
\hline & No & 20.8 & $17.6-24.1$ & \\
\hline \multirow[t]{2}{*}{ Re-operation } & Yes & 15.1 & $10.1-20.2$ & 0.323 \\
\hline & No & 22.5 & $18.5-24.6$ & \\
\hline \multirow[t]{2}{*}{ Adjuvant chemotherapy } & Yes & 25.6 & $21.8-29.4$ & 0.001 \\
\hline & No & 14.3 & $11.0-17.7$ & \\
\hline
\end{tabular}


Table 4 Multivariate risk analysis. Impact of various characteristics on overall survival of all included patients with pancreatic ductal adenocarcinoma after curative intended pancreas surgery $(n=251)$ (Continued)

\begin{tabular}{|c|c|c|c|c|}
\hline & & Survival [months] & $\mathrm{Cl}$ [months] & $p$ \\
\hline \multirow[t]{2}{*}{ Abandonment of chemotherapy } & Yes & 27.7 & $22.6-32.8$ & 0.009 \\
\hline & No & 19.7 & $11.3-281$ & \\
\hline \multirow[t]{3}{*}{ Cycles } & $1-3$ & 14 & $0.2-11.7$ & 0.026 \\
\hline & $4-5$ & 26.3 & $3-20.4$ & \\
\hline & 6 & 27.7 & $1.7-24.4$ & \\
\hline \multirow[t]{2}{*}{ Rehabilitation } & Yes & 21.5 & $18.3-24.8$ & 0.159 \\
\hline & No & 15.1 & $8.2-22.1$ & \\
\hline \multirow[t]{2}{*}{ OP to rehabilitation [days] } & $<21$ & 23.6 & $14.9-32.3$ & 0.419 \\
\hline & $\geq 21$ & 18.5 & $16.5-20.5$ & \\
\hline \multirow[t]{3}{*}{ Tumor localization } & Caput & 20.4 & $17.2-23.5$ & 0.515 \\
\hline & Corpus & 19.4 & $6.2-40.6$ & \\
\hline & Caudae & 22.6 & $11.3-33.8$ & \\
\hline \multirow[t]{4}{*}{ Tumor size } & $\mathrm{T} 1$ & 38.3 & $19.9-56.6$ & 0.212 \\
\hline & $\mathrm{T} 2$ & 20.7 & $15.7-25.8$ & \\
\hline & $\mathrm{T} 3$ & 19.7 & $16.1-23.3$ & \\
\hline & $\mathrm{T} 4$ & 10.1 & $0-21.9$ & \\
\hline \multirow[t]{2}{*}{ Tumor grade } & $\mathrm{G} 1 / \mathrm{G} 2$ & 21.6 & $16.7-26.4$ & 0.019 \\
\hline & G3/G4 & 15.2 & $7.3-23.1$ & \\
\hline \multirow[t]{2}{*}{ Lymph node invasion } & No & 30.6 & $24.2-37.6$ & $<0.001$ \\
\hline & N1 & 17.3 & $1.8-13.8$ & \\
\hline \multirow[t]{2}{*}{ Lymph vessel invasion } & LO & 26.6 & $12.3-41.0$ & 0.014 \\
\hline & L1 & 17.4 & $13.3-21.6$ & \\
\hline \multirow[t]{3}{*}{ Vein invasion } & V0 & 22.6 & $18.5-26.6$ & 0.016 \\
\hline & V1 & 14.4 & $11.5-17.4$ & \\
\hline & V2 & 10.3 & $n / c$ & \\
\hline \multirow[t]{2}{*}{ Perineural invasion } & Pno & 21.6 & $15.3-27.8$ & 0.242 \\
\hline & Pn1 & 19.6 & $14.9-24.3$ & \\
\hline \multirow[t]{2}{*}{ Distant metastases } & Mo & 20.8 & $17.7-24.0$ & 0.012 \\
\hline & M1 & 6.6 & $1.4-17.4$ & \\
\hline \multirow[t]{3}{*}{ Resection } & RO & 24.3 & $19.6-29.2$ & $<0.001$ \\
\hline & $\mathrm{R} 1$ & 13.3 & $10.7-15.9$ & \\
\hline & $\mathrm{R} 2$ & 14.4 & $17.3-23.4$ & \\
\hline \multirow[t]{5}{*}{ CA 19.9 [U/mL] (time of diagnosis) } & $<37$ & 23.6 & $21.3-33.4$ & 0.071 \\
\hline & $<100$ & 27.6 & $24.3-41.0$ & \\
\hline & $<500$ & 18.0 & $18.0-26.3$ & \\
\hline & $<1000$ & 14.1 & $13.3-23.5$ & \\
\hline & $\geq 1000$ & 10.4 & $9.3-27.5$ & \\
\hline \multirow[t]{5}{*}{ CA 19.9 [U/mL] (postoperatively) } & $<37$ & 26.4 & $25.3-32.8$ & 0.031 \\
\hline & $<100$ & 15.9 & $12.2-28.4$ & \\
\hline & $<500$ & 14.4 & $12.3-22.5$ & \\
\hline & $<1000$ & 13.0 & -11.3 to 44.2 & \\
\hline & $\geq 1000$ & 9.9 & $7.2-18.3$ & \\
\hline
\end{tabular}


Table 4 Multivariate risk analysis. Impact of various characteristics on overall survival of all included patients with pancreatic ductal adenocarcinoma after curative intended pancreas surgery $(n=251)$ (Continued)

\begin{tabular}{llll}
\hline & & Survival [months] & Cl [months] \\
\hline CA 19.9 [U/mL] (time of recurrence) & $<37$ & 25.2 & $21.8-35.4$ \\
& $<100$ & 22.5 & $19.0-29.3$ \\
& $<500$ & 23.7 & $20.8-31.1$ \\
& $<1000$ & 16.3 & $14.9-25.0$ \\
& $\geq 1000$ & 10.3 & $10.1-18.0$ \\
\hline
\end{tabular}

Reference range of CA $19.9<37 \mathrm{U} / \mathrm{mL}$

$B M I$ body mass index, $\mathrm{Cl}$ confidence interval, $n / c$ not calculated, $O P$ operation

chemotherapy. Our data indicates that well-tolerated adjuvant chemotherapy with gemcitabine will remain a valuable tool of adjuvant therapy in pancreatic cancer in patients with low-performance status also in times of more effective chemotherapy regimens.

\section{Abbreviations}

5-FU: 5-Fluorouracil; GEM: Gemcitabine; PDAC: Pancreatic ductal

adenocarcinoma

\section{Acknowledgements}

We thank Andrea Klock and the documentary staff of the Comprehensive Cancer Center, for assistance with documentation.

\section{Authors' contributions}

SC, SFF, and UAW are responsible for conception and design. Data was collected by MR, OS, and SC. Data was analyzed by AKL, MR, OS, SC, and UAW. AKL and LK wrote the manuscript with the help of SC. SFF and UAW revised the article. All authors read and approved the final manuscript.

\section{Funding}

No funding was received.

\section{Availability of data and materials}

The datasets used and analyzed during the current study are available from the corresponding author on reasonable request

\section{Ethics approval and consent to participate}

Study was approved by the local ethical committee.

Due to the retrospective study design and the anonymization of data, consent to participate was not necessary. An identification of the participants by third is not possible.

\section{Consent for publication}

Not applicable.

\section{Competing interests}

The authors declare that they have no competing interests.

\section{Author details}

${ }^{1}$ Department of General and Visceral Surgery, Medical Center - University of Freiburg, Faculty of Medicine, University of Freiburg, Hugstetter Straße 55, 79106 Freiburg im Breisgau, Germany. ${ }^{2}$ Center for Complementary Medicine, Institute for Infection Prevention and Hospital Epidemiology, Medical Center - University of Freiburg, Faculty of Medicine, University of Freiburg, Breisacher Straße 115b, 79106 Freiburg im Breisgau, Germany.

Received: 15 July 2019 Accepted: 23 October 2019

Published online: 09 November 2019

\section{References}

1. Garrido-Laguna I, Hidalgo M. Pancreatic cancer: from state-of-the-art treatments to promising novel therapies. Nat Rev Clin Oncol. 2015;12:319-34. https://doi.org/10.1038/nrclinonc.2015.53.
2. Hidalgo M. Pancreatic Cancer. N Engl J Med. 2010;362:1605-17. https://doi.org/10.1056/NEJMra0901557.

3. Siegel RL, Miller KD, Jemal A. Cancer statistics, 2015. CA Cancer J Clin 2015;65:5-29. https://doi.org/10.3322/caac.21254.

4. Leitlinienprogramm Onkologie (Deutsche Krebsgesellschaft - Deutsche Krebshilfe - AWMF). S3-Leitlinie Exokrines Pankreaskarzinom. 2013. https:// www.awmf.org/leitlinien/detail/l//032-0100L.html

5. Conroy T, Ducreux M. Adjuvant treatment of pancreatic cancer. Curr Opin Oncol. 2019;47:S378-80. https://doi.org/10.1097/CCO.0000000000000546.

6. Wu W, He J, Cameron JL, Makary M, Soares K, Ahuja N, et al. The impact of postoperative complications on the administration of adjuvant therapy following pancreaticoduodenectomy for adenocarcinoma. Ann Surg Oncol. 2014;21:2873-81. https://doi.org/10.1245/s10434-014-3722-6.

7. Merkow RP, Bilimoria KY, Tomlinson JS, Paruch JL, Fleming JB, Talamonti MS, et al. Postoperative complications reduce adjuvant chemotherapy use in resectable pancreatic cancer. Ann Surg. 2014;260:372-7. https://doi.org/10. 1097/SLA.0000000000000378.

8. Kneuertz PJ, Pitt HA, Bilimoria KY, Smiley JP, Cohen ME, Ko CY, et al. Risk of morbidity and mortality following hepato-pancreato-biliary surgery. J Gastrointest Surg. 2012;16:1727-35. https://doi.org/10.1007/s11605-012-1938-y.

9. Bilimoria KY, Bentrem DJ, Lillemoe KD, Talamonti MS, Ko CY, Pancreatic Cancer Quality Indicator Development Expert Panel AC of S. Assessment of pancreatic cancer care in the United States based on formally developed quality indicators. J Natl Cancer Inst. 2009;101:848-59. https://doi.org/10. 1093/jnci/djp107.

10. Åkerberg D, Björnsson B, Ansari D. Factors influencing receipt of adjuvant chemotherapy after surgery for pancreatic cancer: a twocenter retrospective cohort study. Scand J Gastroenterol. 2017;52:56-60. https://doi.org/10.1080/00365521.2016.1228118.

11. Adamska A, Domenichini A, Falasca M. Pancreatic ductal adenocarcinoma: current and evolving therapies. Int J Mol Sci. 2017;18:1338. https://doi.org/ 10.3390/ijms18071338.

12. ASA House of Delegates/Executive Committee (American Society of Anaesthesiologists). ASA Physical Status Classification System 2018 https://www.asahq.org/standards-and-guidelines/asa-physical-statusclassification-system (Accessed 18 Apr 2019).

13. American Cancer Society. Pancreas Cancer Staging 2019. https:/cancerstaging org/references-tools/quickreferences/Documents/PancreasSmall.pdf (Accessed 19 Apr 2019).

14. Valle JW, Palmer D, Jackson R, Cox T, Neoptolemos JP, Ghaneh P, et al. Optimal duration and timing of adjuvant chemotherapy after definitive surgery for ductal adenocarcinoma of the pancreas: ongoing lessons from the ESPAC-3 study. J Clin Oncol. 2014;32:504-12. https://doi.org/10.1200/ JCO.2013.50.7657.

15. Epelboym I, Zenati MS, Hamad A, Steve J, Lee KK, Bahary N, et al. Analysis of perioperative chemotherapy in resected pancreatic cancer: identifying the number and sequence of chemotherapy cycles needed to optimize survival. Ann Surg Oncol. 2017;24:2744-51. https://doi.org/ 10.1245/s10434-017-5975-3.

16. Zhang W-Y, Zhang W-J, Bai Y, Yuan H-H, Liu F, Gao J, et al. Impact of adjuvant chemotherapy cycles on prognosis of resectable stomach cancer: a retrospective analysis. Asian Pac J Cancer Prev. 2013;14:381-6.

17. Altman AD, McGee J, May T, Lane K, Lu L, Xu W, et al. Neoadjuvant chemotherapy and chemotherapy cycle number: a national multicentre study. Gynecol Oncol. 2017;147:257-61. https://doi.org/10.1016/j.ygyno.2017.08.006. 
18. Oweira H, Petrausch U, Helbling D, Schmidt J, Mannhart M, Mehrabi A, et al. Prognostic value of site-specific metastases in pancreatic adenocarcinoma: a surveillance epidemiology and end results database analysis. World J Gastroenterol. 2017;23:1872. https://doi.org/10.3748/wjg.v23.i10.1872.

19. Bailey P, Chang DK, Nones K, Johns AL, Patch A-M, Gingras M-C, et al. Genomic analyses identify molecular subtypes of pancreatic cancer. Nature. 2016;531:47-52. https://doi.org/10.1038/nature16965.

20. Toschi L, Finocchiaro G, Bartolini S, Gioia V, Cappuzzo F. Role of gemcitabine in cancer therapy. Future Oncol. 2005;1:7-17. https:/doi.org/10.1517/14796694.1.1.7.

21. Conroy T, Hammel P, Hebbar M, Ben Abdelghani M, Wei AC, Raoul J-L, et al. FOLFIRINOX or gemcitabine as adjuvant therapy for pancreatic cancer. N Engl J Med. 2018;379:2395-406. https://doi.org/10.1056/nejmoa1809775.

22. Klaiber U, Leonhardt C-S, Strobel O, Tjaden C, Hackert T, Neoptolemos JP. Neoadjuvant and adjuvant chemotherapy in pancreatic cancer. Langenbeck's Arch Surg. 2018;403:917-32. https:/doi.org/10.1007/s00423-018-1724-8.

\section{Publisher's Note}

Springer Nature remains neutral with regard to jurisdictional claims in published maps and institutional affiliations.

Ready to submit your research? Choose BMC and benefit from:

- fast, convenient online submission

- thorough peer review by experienced researchers in your field

- rapid publication on acceptance

- support for research data, including large and complex data types

- gold Open Access which fosters wider collaboration and increased citations

- maximum visibility for your research: over $100 \mathrm{M}$ website views per year

At BMC, research is always in progress.

Learn more biomedcentral.com/submissions 